\title{
Incidence of 'Candidatus Liberibacter asiaticus'-Infected Plants Among Citrandarins as Rootstock and Scion Under Field Conditions
}

\author{
Leonardo Pires Boava, Cíntia Helena Duarte Sagawa, Mariângela Cristofani-Yaly, and Marcos Antonio Machado
}

Centro de Citricultura Sylvio Moreira, CP4, 13490-970, Cordeirópolis-São Paulo, Brazil.

Accepted for publication 14 October 2014.

\begin{abstract}
Boava, L. P., Sagawa, C. H. D., Cristofani-Yaly, M., and Machado, M. A. 2015. Incidence of 'Candidatus Liberibacter asiaticus'-infected plants among citrandarins as rootstock and scion under field conditions. Phytopathology 105:518-524.

Huanglongbing (HLB), caused by the bacterium 'Candidatus Liberibacter' spp., is currently one of the most serious diseases of citrus plants and has caused substantial economic losses. Thus far, there is no source of genetic resistance to HLB in the genus Citrus or its relatives. However, several studies have reported Poncirus trifoliata and some of its hybrids to be more tolerant to the disease. The main objective of this study was to report differences in the incidence of ' $\mathrm{Ca}$. L. asiaticus' infection in citrandarin plants, hybrids from Sunki mandarin (Citrus sunki (Hayata) hort. ex Tanaka), and trifoliate orange Rubidoux (P. trifoliata (L.) Raf.)), after conducting an extensive survey under field conditions. These hybrid plants were established for approximately 7 years in an area with a high incidence of ' $\mathrm{Ca}$. L. asiaticus'-infected plants. We selected two

experimental areas (area A and area B), located approximately $10 \mathrm{~m}$ apart. Area A consists of Pera sweet orange (C. sinensis (L.) Osb.) grafted onto 56 different citrandarin rootstocks. Area B consists of citrandarin scions grafted onto Rangpur lime (C. limonia Osb.) rootstock. Bacteria in the leaves and roots were detected using real-time quantitative polymerase chain reaction. The incidence of ' $\mathrm{Ca}$. $\mathrm{L}$. asiaticus'-infected plants was $92 \%$ in area A and $14 \%$ in area B. Because infected plants occurred in both areas, we examined whether the $P$. trifoliata hybrid rootstock influenced HLB development and also determined the distribution of ' $\mathrm{Ca}$. L. asiaticus' in Citrus tree tissues. Although this survey does not present evidence regarding the resistance of $P$. trifoliata and its hybrids in relation to bacteria or psyllids, future investigation, mainly using the most promising hybrids for response to 'Ca. L. asiaticus', will help us to understand the probable mechanism of defense or identifying compounds in $P$. trifoliata and its hybrids that are very important as strategy to combat HLB. Details of these results are presented and discussed in this article.
\end{abstract}

Citrus huanglongbing (HLB) is one of the most important citrus diseases worldwide, causing severe losses in commercial citrus production wherever the disease occurs (10). The disease was found in São Paulo State, Brazil in 2004 (8) and in Florida in the United States in 2005 (16). The causative agent, 'Candidatus Liberibacter' sp., a class $\alpha$-proteobacteria, has not been reliably cultured yet, and there are three HLB-associated Liberibacter spp.: 'Candidatus Liberibacter asiaticus', ' $\mathrm{Ca}$. L. africanus', and ' $\mathrm{Ca}$. L. americanus' (7). Among these, ' $\mathrm{Ca}$. L. asiaticus' is the most widespread and is responsible for increasing economic losses in recent years. ' $\mathrm{Ca}$. L. asiaticus' can distribute unevenly in bark, leaf midribs, roots, floral tissues (petals, pistils, and stamens), and fruit tissues.

'Ca. Liberibacter' spp. are transmitted by the psyllids Diaphorina citri in most citrus-growing regions, and Trioza eritreae in Africa. Both psyllid species can transmit all species of ' $\mathrm{Ca}$. Liberibacter' and are attracted to volatiles emitted from flushing shoots (26). The spread of HLB within a citrus grove has been attributed to the movement of $D$. citri from infected trees to healthy trees. Within a grove, the rate and range of HLB spread is directly dependent on the dispersal range of $D$. citri. Likewise, the spread of HLB from one grove to another probably depends on the dispersal range of $D$. citri $(14,17)$. Some Citrus spp. and relatives are apparently less preferred hosts to the psyllid $(28,29)$ and they may influence the development, longevity, and reproduction of $D$. citri.

Infected trees respond to the bacteria with numerous physiological reactions, resulting in a sequence of symptoms characterized by

Corresponding author: M. Cristofani-Yaly;

E-mail address: mariangela@centrodecitricultura.br

http://dx.doi.org/10.1094/PHYTO-08-14-0211-R

(C) 2015 The American Phytopathological Society blotchy mottling with green islands on leaves. Symptoms of HLB appear to be associated with phloem collapse and blockage of translocation streams (1). Infected sprouts are stunted, and the branches gradually die as the disease progresses. HLB greatly damages the citrus industry by shortening tree lifespan, reducing fruit yield, and reducing quality characteristics such as total soluble solids, acidity, and total soluble solids/acidity ratio (10).

Strategies for HLB control and appropriate management include applying insecticide for vector control, planting pathogen-free nursery stock, and removing inoculum by destroying infected trees (15). A more sustainable approach for HLB management would be to cultivate citrus cultivars that are unaffected, or resistant to infection (13).

All commercial Citrus spp. and scion cultivars are susceptible to 'Ca. L. asiaticus' infection (7). Among commercial Citrus varieties, sweet orange (Citrus sinensis L.), mandarin (C. reticulata Blanco), and tangelo (hybrids of $C$. reticulata and $C$. paradisi) are most susceptible. However, a recent analysis of the different Citrus genotypes indicated that there are differences in host response to HLB. Tolerance to ' $\mathrm{Ca}$. L. asiaticus' has been reported for some cultivars commonly used as rootstocks, particularly Poncirus trifoliata and some of its hybrids (11). A recent study identified the trifoliate hybrid US-897 (C. reticulata $\times$ P. trifoliata) as tolerant to HLB (2). Transcriptional analysis of US-897 discovered a number of genes potentially associated with tolerance to ' $\mathrm{Ca}$. L. asiaticus' (3). Little is known regarding the effects of rootstocks on HLB development in scions typically used for commercial citrus production.

Accurate identification of ' $\mathrm{Ca}$. Liberibacter' spp. is needed to facilitate management of infected trees. Several factors can affect detection accuracy, including physical and environmental conditions, nutritional deficiencies (similar to zinc or other nutrient deficiencies), drought stress, leaf diseases, and latency period of the 
bacterium within the tree (12). In the field, visual detection is based primarily on leaf or fruit patterns. However, visual diagnosis can be problematic due to uneven and varying symptoms associated with ' $C a$. L. asiaticus' within in the tree. Studies performed by Fucth et al. (12), indicated that no survey method was $100 \%$ accurate at identifying all trees that exhibited several disease stages. Because HLB diagnosis based on disease symptoms can be difficult due to other biotic or abiotic plant-health-related problems (7), real-time quantitative polymerase chain reaction (qPCR) has become the preferred method for detecting ' $\mathrm{Ca}$. Liberibacter' spp. qPCR has gained acceptance because of its improved speed, sensitivity, reproducibility, robustness, and reduced risk of carry-over contamination compared with standard PCR (21).

Our group has been conducting a broad program to genetically improve citrus trees using controlled crosses $(6,9)$. Populations of plants obtained from controlled crosses between different species and varieties of citrus were used to create an extensive network of potential new genotypes. Among them is an $F_{1}$ population of 275 individuals of interspecies crosses between $C$. sunki and $P$. trifoliata (citrandarin). In a previous study with this population using graft inoculation in a greenhouse, we observed differences in the multiplication of ' $\mathrm{Ca}$. L. asiaticus' in both parents and in the progeny; the infection rate was higher in $C$. sunki compared with $P$. trifoliata, and wide variation occurred among the hybrids.

The present study was conducted to detect differences in ' $\mathrm{Ca}$. L. asiaticus' incidence among these hybrids in the field. These hybrids were established as scions in the field approximately 7 years ago in an area with high rates of HLB incidence and with no appropriate HLB management. In this area, there are also trees of Pera sweet orange grafted onto different citrandarin hybrids. The objective of this work was to monitor the development of ' $\mathrm{Ca}$. L. asiaticus' in citrandarin used as scions and as rootstocks with high pressure of infection under field conditions.

\section{MATERIALS AND METHODS}

Plant material. We selected two experimental fields located approximately $10 \mathrm{~m}$ apart to observe the incidence of ' $\mathrm{Ca}$. $\mathrm{L}$. asiaticus'-infected plants among citrandarin (hybrids of $C$. sunki and $P$. trifoliata $)$ and Pera sweet orange $(C$. sinensis) trees grafted onto different citrandarin as rootstocks (Fig. 1). These areas were located in Cordeirópolis-São Paulo, Brazil, one of the region of this state most affected by HLB epidemics. Both experiments started with disease-free nursery plants produced under insect-proof greenhouses. The trees were established for approximately 7 years in the field in an area with a high incidence of HLB and no appropriate HLB management. However, since 2007, inspection and removal of HLB-symptomatic trees was carried out three to four times per year.

Area A consisted of 172 trees of Pera sweet orange grafted onto 56 different hybrids of citrandarin, with three replicates. These trees were asymptomatic based on visual detection of HLB. Area B consisted of $275 \mathrm{~F}_{1}$ individuals of citrandarin grafted onto Rangpur lime rootstock planted in 2006, with three replicates. The trifoliate orange in this area did not display any well-defined leaf symptoms for HLB visual detection; thus, symptomatic trees were not removed during inspections.

Leaf sampling and DNA isolation. Leaf samples for ' $\mathrm{Ca}$. L. asiaticus' quantification were collected from all trees in both areas. Leaves of similar age and position from four sides of the scion were collected. Petioles of 16 leaves from each tree were combined, and 200-mg subsamples were ground with two beads $(3 \mathrm{~mm}$ in diameter) in 2-ml microtubes at $30 \mathrm{~Hz}$ for $120 \mathrm{~s}$ using TissueLyser II (Qiagen). DNA extraction was carried out using the cetyltrimethylammonium bromide method, as previously described (25). Precipitated DNA was dissolved in $50 \mu \mathrm{l}$ of DNAse-free water. The quality of the DNA samples was checked by electrophoresis in $1.2 \%$ agarose gels. DNA concentrations were determined in
ND-1000 Spectrophotometer (NanoDropTechnologies) and adjusted to $100 \mathrm{ng} / \mu \mathrm{l}$.

Leaf and root sampling and DNA isolation. After a survey of the incidence of ' $\mathrm{Ca}$. L. asiaticus', we selected some plants from area A and some from area B for ' $\mathrm{Ca}$. L. asiaticus' quantification to verify whether Poncirus hybrids used as rootstock influenced HLB development, and to observe the distribution of ' $\mathrm{Ca}$. L. asiaticus' in citrus tree tissues. We collected leaf and root samples from four sides of the plants from (i) five ' $\mathrm{Ca}$. L. asiaticus'-positive hybrids, (ii) five ' $C a$. L. asiaticus'-negative hybrids, (iii) five ' $C a$. L. asiaticus'-positive Pera sweet orange trees, and (iv) five ' $\mathrm{Ca}$. L. asiaticus'-negative Pera sweet orange trees. The hybrids were grafted onto Rangpur lime, and Pera sweet orange was grafted onto various different hybrids. Subsamples $(200 \mathrm{mg}$ ) of the tissues were ground and DNA was extracted as described above.

Rootstock shoot and scion shoot sampling and DNA isolation. We detected 37 trees with shoots from the Rangpur lime rootstock in area B (Fig. 2). We selected some of these plants to examine the distribution of ' $\mathrm{Ca}$. L. asiaticus' in leaves from the scion (from four sides of the plants) and leaves from the rootstock from (i) five plants with ' $\mathrm{Ca}$. L. asiaticus'-positive shoots and ' $C a$. L. asiaticus'-positive hybrid scions, (ii) five plants with ' $C a$. L. asiaticus'-positive shoots and ' $\mathrm{Ca}$. L. asiaticus'-negative hybrid scions, and (iii) five plants with ' $\mathrm{Ca}$. L. asiaticus'-negative shoots and ' $\mathrm{Ca}$. L. asiaticus'-negative hybrid scions. Next, $200 \mathrm{mg}$ of each petiole sample was ground and DNA extraction was performed as describe above.

' $\boldsymbol{C a}$. L. asiaticus' detection. The presence of ' $\mathrm{Ca}$. L. asiaticus' was determined by qPCR amplifications using sets of $16 \mathrm{~S}$ ribosomal DNA (rDNA) primers and FAM/Iowa Black FQ label probe (IDT Inc., Coralville, IA), as described by Li (20). The target fragment of ' $\mathrm{Ca}$. L. asiaticus' amplified by primer set was electrophoresed on $2 \%$ agarose gel. The expected target band was cut out in situ and purified with a Qiaquick gel extraction kit (Qiagen), according to the manufacturer's instructions. The DNA was eluted and used for ligation with the pGEM-T vector (Promega Corp.). Recombinant plasmid solution was used to transform competent Escherichia coli DH5 $\alpha$. The recombinant plasmid was extracted with a Pure Yield Plasmid Miniprep System (Promega Corp.), following the manufacturer's instructions, and was sequenced and aligned using blastn. The original plasmid standard solution was quantified with ND-1000 Spectrophotometer (NanoDropTechnologies), then diluted in 10-fold serial dilutions from the original solution of target DNA $10^{-10}$, the dilutions being used to

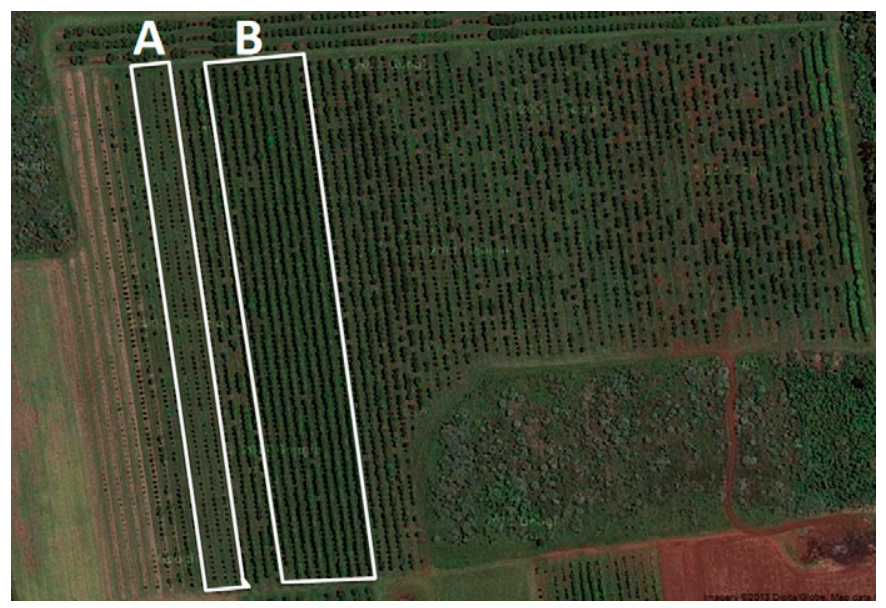

Fig. 1. Aerial view of the citrus experimental areas with no appropriate huanglongbing management. A, Pera sweet orange trees (Citrus sinensis) grafted onto different hybrids with three replicates. B, $F_{1}$ population of an interspecies cross between $C$. sunki and Poncirus trifoliata grafted onto Rangpur lime (C. limonia Osbeck). 
generate a standard curve. With the standard-curve method, we could calculate the titer of bacteria. The ' $\mathrm{Ca}$. L. asiaticus' quantification (copy number [CN] of $16 \mathrm{~S}$ rDNA per microliter) was based on the formula $\mathrm{CN}=(M \times N) /(L \times D)$, where $M=$ minimum concentration of nucleic acid detected $\left(\mathrm{g} \mathrm{ml}^{-1}\right), N=$ Avogadro's number $\left(6.022 \times 10^{23}\right.$ molecules $\left.\mathrm{mol}^{-1}\right), L=$ length of nucleic acid in kilobase pairs (total length of plasmid + insert of LaGX10 fragment), and $D=$ conversion factor from $1 \mathrm{~kb}$ of nucleic acid to Daltons (double-stranded DNA $=6.6 \times 10^{5} \mathrm{~g} \mathrm{~mol}^{-1} \mathrm{~kb}^{-1}$ ), according to Wang et al. (31). qPCR amplifications were performed using $14 \mu \mathrm{l}$ of reactions containing $6.25 \mu \mathrm{l}$ of $1 \times$ TaqMan Universal Master Mix (Applied Biosystem), $216 \mathrm{nM}$ each of the primers HLBas and HLBr, and $135 \mathrm{nM}$ each of the probes HLBp in an ABI PRISM 7500 Sequence Detection System (Applied Biosystem) thermocycler (20). GAPDH was used as an internal control gene with $270 \mathrm{nM}$ each primer and $135 \mathrm{nM}$ each probe. Water was added to bring the volume to $11 \mu \mathrm{l}$, and $3 \mu \mathrm{l}$ of template was used per reaction. All reactions were performed in duplicate. Each PCR assay of 96 sample wells contained the following controls: two wells with water (no template control [NTC]) as negative PCR controls and two wells containing ' $\mathrm{Ca}$. L. asiaticus'-positive DNA extraction as positive controls. The PCR cycling conditions were $95^{\circ} \mathrm{C}$ for $5 \mathrm{~min}$ followed by 40 cycles of $95^{\circ} \mathrm{C}$ for $30 \mathrm{~s}$ and $58^{\circ} \mathrm{C}$ for $45 \mathrm{~s}$. The emissions were measured at each of the 40 extension steps. The cycle threshold $(\mathrm{Ct})$ value is the number of the PCR cycles at which the fluorescence increases above the threshold value. Preliminary optimization of reagent concentrations, including primers and probes, was carried out using known positive and negative DNA extractions, as well as dilutions from the plasmid pLas. A Ct value above 34 was considered negative for ' $\mathrm{C} a$. L. asiaticus' infection under the present experimental conditions.

\section{RESULTS}

The distribution of infected plants with ' $\mathrm{Ca}$. L. asiaticus' in both areas is presented in Figure 3. We identified 92\% ' $\mathrm{Ca}$. L. asiaticus'positive plants in area A and 14\% in area B (Tables 1 and 2). In area A, 'Ca. L. asiaticus'-positive plants were homogeneously distributed between the rows, with 94, 90, and 90\% incidence. In contrast, in area $\mathrm{B}$, ' $\mathrm{Ca}$. L. asiaticus' incidence was not homogeneous between the rows, and ranged from 6.1 to $38.1 \%$ in the eighth and first rows, respectively.

In area A, 8.13\% (14 of 172) of the plants were not infected with ' $\mathrm{Ca}$. L. asiaticus'. Of these ' $\mathrm{Ca}$. L. asiaticus'-negative plants, only two were grafted onto the same rootstock (hybrid 245), and the rest were grafted onto different rootstocks. In area B, $67 \%$ of plants had no infected replicates, $26.3 \%$ of plants had one infected replicate, and $6.7 \%$ of plants had two infected replicates. Therefore, $32.9 \%$ plants had at least one infected replicate. There were no plants with all three replicates infected (Table 3 ).
Based on the results for HLB incidence in area B, we collected roots and leaves from five ' $\mathrm{Ca}$. L. asiaticus'-negative and five ' $\mathrm{Ca}$. L. asiaticus'-positive plants. The samples were obtained from four sides of the plant and were analyzed individually (Table 4). For the ' $C a$. L. asiaticus'-negative plants, no leaves on any side of the scion were infected. Two of the root samples were not infected but three were infected, despite an uninfected canopy. For the ' $\mathrm{Ca}$. L. asiaticus'-positive plants, leaf samples from at least two sides of the scion were infected. Only one of the root samples was uninfected (hybrid 135) but all other root samples were infected.

We collected root and leaf samples from five ' $\mathrm{Ca}$. L. asiaticus'negative and five ' $C a$. L. asiaticus'-positive plants from area A

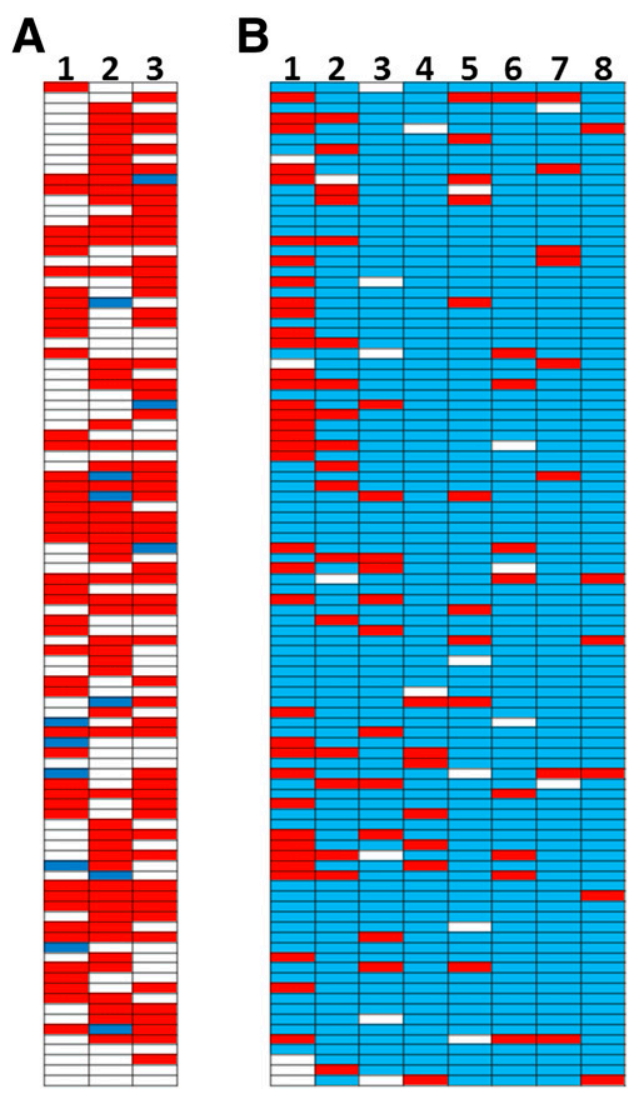

Fig. 3. Incidence of 'Candidatus Liberibacter asiaticus'-infected plants in an area with high rates of infection and with no appropriate huanglongbing (HLB) management. A, Pera sweet orange trees (Citrus sinensis) grafted onto different hybrids ( $C$. sunki and Poncirus trifoliata) with three replicates. B, $\mathrm{F}_{1}$ population of an interspecies cross between the $C$. sunki and P. trifoliata grafted onto Rangpur lime $(C$. limonia Osbeck). Blue $=$ HLB negative, red = HLB positive, and white $=$ missing tree .
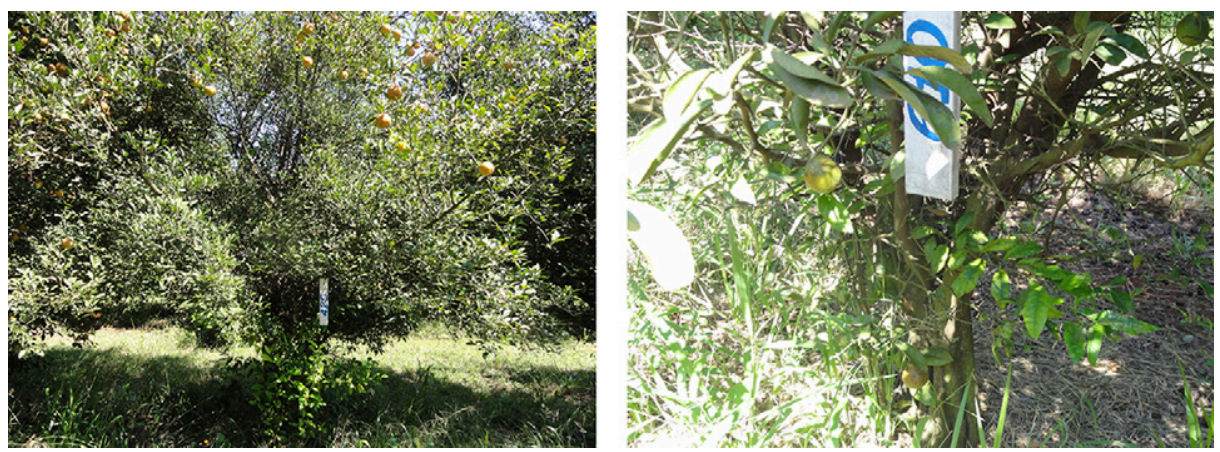

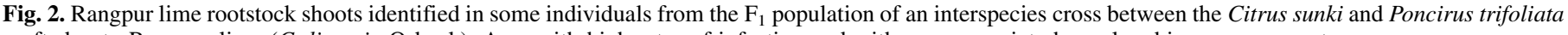
grafted onto Rangpur lime (C. limonia Osbeck). Area with high rates of infection and with no appropriate huanglongbing management. 
based on the incidence of HLB. The samples were obtained from four sides of the plant and were analyzed individually (Table 5). For the ' $C a$. L. asiaticus'-positive plants, all leaves were infected, and for the ' $\mathrm{Ca}$. L. asiaticus'-negative plants, no leaves were infected. None of the root samples from either the ' $\mathrm{Ca}$. L. asiaticus'-negative or ' $C a$. L. asiaticus'-positive plants were infected.

The distribution of the plants in area B that were infected or uninfected with ' $\mathrm{Ca}$. L. asiaticus' is presented in Figure 4. This survey allowed us to identify 27 rootstock shoots that were infected with ' $\mathrm{Ca}$. L. asiaticus', which represents $72 \%$ (27 of 37) of the plants with shoots from the Rangpur rootstock. Next, we examined the distribution of ' $\mathrm{Ca}$. L. asiaticus' between the hybrid scions and shoots of the Rangpur rootstock.

The results were as follows. (i) Leaf samples from plants with ' $C a$. L. asiaticus'-positive shoots and ' $C a$. L. asiaticus'-positive hybrid scions were infected on at least one side of the scion and, for the root samples, only one hybrid was not infected but the other four were infected. (ii) Leaf samples from plants with ' $\mathrm{Ca}$. L. asiaticus'positive shoots and ' $\mathrm{Ca}$. L. asiaticus'-negative hybrid scions were not infected on any side of the scion and, for the root samples, three plants were infected and two were not infected despite infection of the Rangpur lime rootstock shoots. (iii) Leaf samples from plants with ' $\mathrm{Ca}$. L. asiaticus'-negative shoots and ' $\mathrm{Ca}$. L. asiaticus'negative hybrid scions were not infected on any side of the scion; however, one root sample was infected on two sides of the plant, despite uninfected Rangpur lime rootstock shoots (Table 6).

\section{DISCUSSION}

A relevant approach to assessing the differences between HLBtolerant genotypes is to evaluate trees in a field exposed to high rates of HLB incidence and a history of no appropriate vector management. Studies in greenhouses using graft inoculations have been conducted to compare the response of cultivars to HLB but the results may not represent tree performance in the field (28). HLB symptoms developed in approximately $20 \%$ of grafted plants within 3 to 12 months after grafting but the same cannot be assumed for large trees under field situations (29). In our study, we evaluated plants after several years of growth, infection, and expression of disease symptoms under natural exposure to ' $\mathrm{Ca}$. L. asiaticus'.

TABLE 1. Incidence of 'Candidatus Liberibacter asiaticus' in area A, which contained 172 Pera sweet orange trees (Citrus sinensis) grafted onto 56 different hybrid rootstocks

\begin{tabular}{lccc}
\hline Row & $\begin{array}{c}\text { Number } \\
\text { of trees }\end{array}$ & $\begin{array}{c}\text { Number 'Ca. } \\
\text { L. asiaticus' positive }\end{array}$ & $\begin{array}{c}\text { Positive } \\
(\%)\end{array}$ \\
\hline Row 1 & 53 & 48 & 90.6 \\
Row 2 & 60 & 54 & 90.0 \\
Row 3 & 59 & 56 & 94.9 \\
Total & 172 & 158 & 91.9 \\
\hline
\end{tabular}

TABLE 2. Incidence of 'Candidatus Liberibacter asiaticus'-infected plants in area $\mathrm{B}$, which contained $275 \mathrm{~F}_{1}$ individuals from an interspecies cross between the Citrus sunki and Poncirus trifoliata grafted onto Rangpur lime (C. limonia Osbeck) with three replicates

\begin{tabular}{lccc}
\hline Row & $\begin{array}{c}\text { Number } \\
\text { of trees }\end{array}$ & $\begin{array}{c}\text { Number of 'Ca. } \\
\text { L. asiaticus' positive }\end{array}$ & $\begin{array}{c}\text { Positive } \\
(\%)\end{array}$ \\
\hline Row 1 & 93 & 36 & 38.7 \\
Row 2 & 94 & 18 & 19.1 \\
Row 3 & 90 & 11 & 12.2 \\
Row 4 & 95 & 7 & 7.4 \\
Row 5 & 89 & 10 & 11.2 \\
Row 6 & 95 & 9 & 9.5 \\
Row 7 & 96 & 8 & 8.3 \\
Row 8 & 98 & 6 & 6.1 \\
Total & 750 & 105 & 14.0 \\
\hline
\end{tabular}

Methods for early detection of the disease are limited; therefore, epidemiological models of HLB spread are based on symptoms and assume a linear relationship between infection and symptom expression. Manjunath et al. (22) highlighted some factors that could affect the epidemiological model based on HLB symptoms; for example, $48 \%$ of HLB-symptomatic trees in a citrus block were not detected after an inspection, and the latency period for the disease prior to symptom expression under field conditions is not clear. Transmission rates reported in earlier studies of HLB may be unreliable because they were dependent on the development of disease symptoms in host plants rather than the presence or absence of pathogens determined by PCR testing (18). Thus, in our study, the survey was carried out using qPCR, which has gained acceptance, particularly considering its improved features compared with standard PCR (21).

Our results confirmed that there were differences in ' $\mathrm{Ca}$. L. asiaticus' incidence between the areas evaluated in the study (Fig. 3; Tables 2 and 3). Area B (citrandarin as scions) had a low incidence of ' $\mathrm{Ca}$. L. asiaticus' (14\%), whereas area A (Pera sweet orange grafted onto 56 different citrandarin hybrids) had a high ' $\mathrm{Ca}$. L. asiaticus' incidence (92\%). The present analysis was based on results from two nearby areas, located approximately $10 \mathrm{~m}$ apart. Thus, there was no noteworthy effect of temperature or other environmental factors on acquisition, survival, and multiplication of ' $\mathrm{Ca}$. L. asiaticus' in psyllids or transmission of the bacteria to the plants. Trees in both areas experienced 7 years of environmental conditions, inadequate pesticide treatment, and continuous availability of new flushes of psyllids, which may have aided the survival of psyllids and ' $\mathrm{Ca}$. L. asiaticus'. These conditions are ideal for both areas becoming totally infected. Therefore, any differences in disease incidence among the trees may be due to differences in several factors, such as attractiveness of trees to psyllids, ' $\mathrm{Ca}$. L. asiaticus' proliferation following inoculation by psyllids, systemic movement of bacteria with subsequent further proliferation, and the possibility that different genotypes have different tolerances to psyllids and ' $\mathrm{Ca}$. L. asiaticus'.

In this study, no attempt was made to collect psyllids from the same location to analyze their seasonal changes. It is known that the chance of new infections depends on the population density in surrounding plantings and is increased by a high migratory flux of adult psyllids to healthy plantings under good management (5). However, considering that the two experimental areas are located approximately $10 \mathrm{~m}$ from each other, it is unlikely that the insect migration from surrounding plantings would be different between the two areas, because even citrus plantings with an intensive psyllid control program are constantly subjected to new primary infections.

We observed that, in area B, ' $\mathrm{Ca}$. L. asiaticus' incidence was not homogeneous between the rows of trees, and ranged from 6.1 to $38.7 \%$ in the eighth and first rows, respectively. However, this finding was probably not because of primary infections, because any insect control was performed during the whole period in all surrounding areas where high rates of infection were detected (data not shown). If the surrounding infected plantings and the adjacent residential trees are not as rigorously managed, then any trees will be overwhelmed with continuous primary infection via migrating infected vectors (13).

TABLE 3. Number of hybrids infected with 'Candidatus Liberibacter asiaticus' in relation to the number of replicates

\begin{tabular}{lcc}
\hline 'Ca. L. asiaticus'-positive/replicate & Number of hybrids & Incidence (\%) \\
\hline $0 / 3$ & 181 & 67.0 \\
$1 / 3$ & 71 & 26.3 \\
$2 / 3$ & 18 & 6.7 \\
$3 / 3$ & 0 & 0.0 \\
Hybrids with at least one positive & 89 & 32.9 \\
\hline
\end{tabular}


One of the likely causes for the differences in disease incidence, whether between the areas or within areas (rows), could be the faster distribution of the pathogen within the area, attributed to the movement of psyllids from infected trees to healthy trees. Adult psyllids are more attracted to ' $\mathrm{Ca}$. L. asiaticus'-infected trees before feeding on them but they are more attracted to uninfected trees after feeding on infected ones, which may promote the spread of the pathogen (23). Furthermore, some volatiles may interfere with the ability of psyllids to locate and infect citrus (24). P. trifoliata seems to have antixenosis-type resistance because psyllids do not colonize this species in field surveys (32) or lay eggs on it as much they do on other Citrus spp. Perhaps a plant volatile repels psyllids or a plant volatile necessary for attraction is lacking. However, it should be highlighted that the plants are hybrids of mandarin and Poncirus spp. and they should have different levels of attraction compared with Poncirus plants. Several other factors may have influenced these results and contributed to cultivar responses, such as differences in tree age, tree size, and flushing pattern, and also coincidences among flushes, pest control, and psyllid outbreaks. This hypothesis is supported by the results from area B. In this area, consisting of hybrid scions, we also detected 37 trees with shoots from the Rangpur lime rootstock, and $72 \%$ of these trees had infected rootstock leaves.

Although most species in the genus Citrus and its relatives are common hosts of psyllids, some genotypes have the potential to differentially influence the development, longevity, and repro- duction of psyllids (30). P. trifoliata may be useful in breeding programs as a potential source of genes that confer resistance to multiple species of insects and may ultimately lower ' $C a$. L. asiaticus' incidence (27). Very low abundances of psyllids were found in association with genotypes of $P$. trifoliata in a field survey and nearly all genotypes of $P$. trifoliata were found to be resistant to psyllids in no-choice tests (32). According to Richardson and Hall (27), resistance to psyllids is likely conferred by chemical mechanisms and not by the structural characteristics of the plant; psyllids were found to settle to feed on Poncirus spp. in no-choice tests and insert their stylets into phloem cells similar to insects feeding on susceptible plants.

Another possibility for the lower incidence of ' $\mathrm{Ca}$. L. asiaticus' in area B compared with area A could be the potential for Poncirus hybrids to suppress bacterial multiplication in infected tissues. Characterization of the mechanism by which the pathogen manifests in different host plant genotypes is important for predicting how the disease spreads (32). P. trifoliata and some of its hybrids are among few reported genotypes, in which distinct disease symptoms are often not apparent despite the infection. Albrecht and Bowman (2) identified the Poncirus hybrid US-897 (C. reticulata $\times$ $P$. trifoliata) as tolerant to HLB. They observed that graft inoculation of US-897 seedlings under controlled conditions confirmed the observations under field conditions, indicating that tolerance of this genotype is not related to different flushing patterns or feeding preference of the insect vectors. It is possible that compounds

TABLE 4. Incidence of 'Candidatus Liberibacter asiaticus' among hybrids of Citrus sunki and Poncirus trifoliata grafted onto Rangpur lime (C. limonia Osbeck) ${ }^{\mathrm{a}}$

\begin{tabular}{|c|c|c|c|c|c|c|c|c|}
\hline \multirow[b]{3}{*}{ Plants } & \multicolumn{8}{|c|}{$16 \mathrm{~S}$ rDNA CN/ $/ \mu 1^{\mathrm{b}}$} \\
\hline & \multicolumn{4}{|c|}{ Leaves (hybrids) } & \multicolumn{4}{|c|}{ Roots (Rangpur lime) } \\
\hline & A & $\mathrm{B}$ & $\mathrm{C}$ & $\mathrm{D}$ & A & $\mathrm{B}$ & $\mathrm{C}$ & $\mathrm{D}$ \\
\hline H135 & - & - & - & - & - & $3.40 \mathrm{E}+03$ & - & $9.73 E+03$ \\
\hline $\mathrm{H} 245$ & - & - & - & - & $1.34 \mathrm{E}+02$ & $2.58 \mathrm{E}+01$ & - & - \\
\hline H106 & - & - & - & - & - & - & $1.31 \mathrm{E}+04$ & - \\
\hline H113 & - & - & - & - & - & - & - & - \\
\hline H80 & - & $9.27+04$ & - & $5.62 \mathrm{E}+05$ & - & $1.53 \mathrm{E}+04$ & - & - \\
\hline H113 & - & $2.58 \mathrm{E}+01$ & $6.51 \mathrm{E}+02$ & - & - & $4.36 \mathrm{E}+01$ & $3.24 \mathrm{E}+04$ & $9.96 \mathrm{E}+01$ \\
\hline H82 & $8.60 \mathrm{E}+04$ & $5.91 \mathrm{E}+04$ & $4.71 \mathrm{E}+02$ & $2.46 \mathrm{E}+05$ & $5.06 \mathrm{E}+01$ & $5.08 \mathrm{E}+04$ & $1.91 \mathrm{E}+04$ & - \\
\hline H99 & $5.46 \mathrm{E}+01$ & $1.29 \mathrm{E}+06$ & - & - & $3.07 \mathrm{E}+02$ & $2.79 \mathrm{E}+04$ & $9.03 \mathrm{E}+03$ & $2.78 \mathrm{E}+01$ \\
\hline H135 & $9.73 \mathrm{E}+03$ & $1.25 \mathrm{E}+05$ & $7.95 \mathrm{E}+01$ & - & - & - & - & - \\
\hline
\end{tabular}

a Incidence of ' $\mathrm{Ca}$. L. asiaticus' in roots and leaves from five ' $\mathrm{Ca}$. L. asiaticus'-negative plants (Negative) and five ' $C a$. L. asiaticus'-positive plants (Positive).

b Copy number $(\mathrm{CN})$ means of three replicates. $\mathrm{A}, \mathrm{B}, \mathrm{C}$, and $\mathrm{D}=$ samples taken from four sides of the plants; - indicates undetermined cycle threshold value.

TABLE 5. Incidence of 'Candidatus Liberibacter asiaticus'-infected Pera sweet orange trees (Citrus sinensis) grafted onto different hybrids ${ }^{\mathrm{a}}$

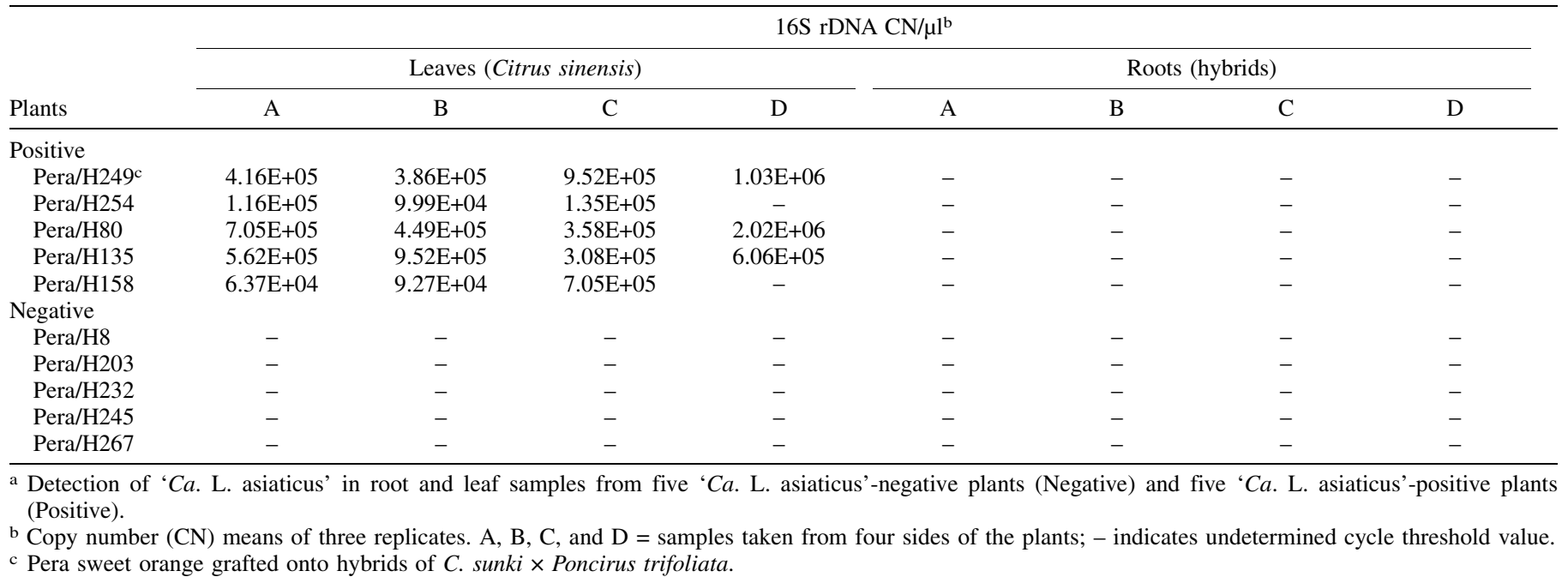




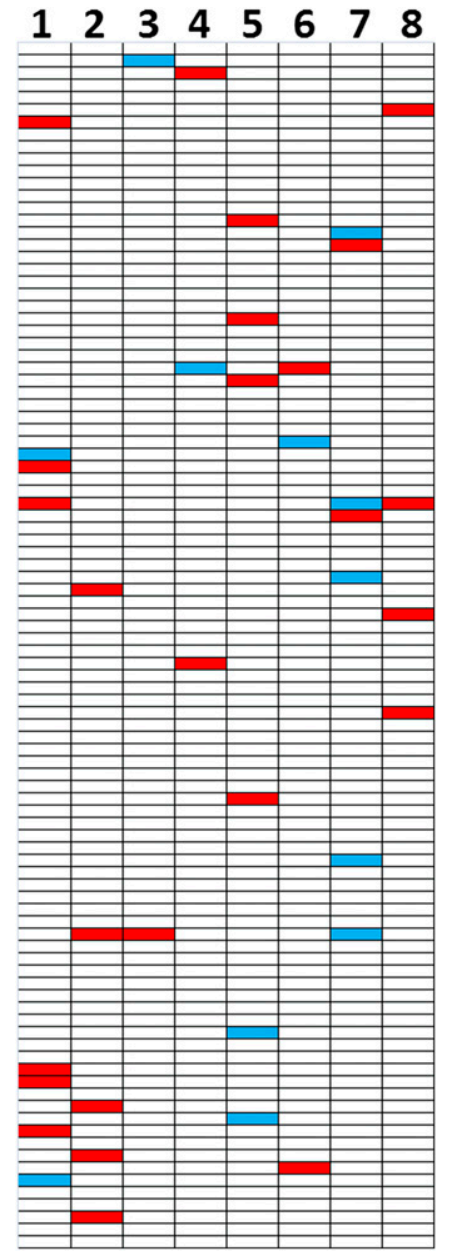

Fig. 4. Incidence of 'Candidatus Liberibacter asiaticus'-infected plants with Rangpur lime rootstock shoots in an area with high rates of infection and with no appropriate huanglongbing (HLB) management. This area has an $\mathrm{F}_{1}$ population of an interspecies cross between the Citrus sunki and Poncirus trifoliata grafted on Rangpur lime (C. limonia Osbeck). Blue = HLB negative, red $=$ HLB positive, and white $=$ plants with no rootstock shoots. restricting ' $\mathrm{Ca}$. L. asiaticus' proliferation or movement within the phloem are present, resulting in tolerance of Poncirus spp. and their hybrids to HLB (3).

Another purpose of this study was to investigate whether a Poncirus hybrid used as a rootstock influences HLB development in sweet orange scions under natural conditions in the field. In area A, where 172 Pera sweet orange trees $(C$. sinensis) were grafted onto 56 different hybrids, the incidence of ' $\mathrm{Ca}$. L. asiaticus' was $92 \%$; thus, only 14 plants were not infected. Of these ' $\mathrm{Ca}$. L. asiaticus'negative plants, two were grafted onto the same rootstock (hybrid 245). Albrecht et al. (4) investigated whether rootstock selection had an effect on HLB development under natural field conditions. The study showed that rootstocks presented no significant change in disease incidence and trees on all rootstocks were considerably damaged by HLB. However, tolerance to ' $\mathrm{Ca}$. L. asiaticus' was higher in trees grafted onto some rootstock selections such as varieties of trifoliate hybrid rootstock, which improved scion performance.

Our data also provide experimental evidence that ' $\mathrm{Ca}$. L. asiaticus' is unevenly distributed between the tissues of citrus trees. Based on the results of HLB incidence between citrandarin plants, we collected root samples from five ' $\mathrm{Ca}$. L. asiaticus'-negative plants and five ' $\mathrm{Ca}$. L. asiaticus'-positive plants. From ' $\mathrm{Ca}$. L. asiaticus'-negative plants, root samples from two hybrids were not infected and three of them were infected, even with an uninfected scion. Root samples from all ' $\mathrm{Ca}$. L. asiaticus'-positive plants were infected, with the exception of only one hybrid (hybrid 135) (Table 4).

We also collected root samples of five ' $\mathrm{Ca}$. L. asiaticus'-negative and five ' $\mathrm{Ca}$. L. asiaticus'-positive plants of Pera sweet orange grafted onto different hybrid rootstocks. Although ' $\mathrm{Ca}$. L. asiaticus' was not present at detectable levels in the roots of these trees, it was present in the leaves at higher titers (Table 5). Thus, these results do not conflict with the widely held belief that the distribution of ' $C a$. L. asiaticus' in plant tissues is irregular. It is likely that these trees represent an early stage of disease progression, in which the pathogen is moving toward but has not yet reached and colonized the roots, or that Poncirus hybrids suppress ' $\mathrm{Ca}$. L. asiaticus' multiplication in the roots. Johnson et al. (19) showed the importance of root infection in disease development. However, in their study, in contrast to our finding, ' $C a$. L. asiaticus' preferentially colonized

TABLE 6. Incidence of 'Candidatus Liberibacter asiaticus' in hybrids of Citrus sunki and Poncirus trifoliata grafted onto Rangpur lime and with sprouting of Rangpur lime rootstock (C. limonia Osbeck) ${ }^{\mathrm{a}}$

\begin{tabular}{|c|c|c|c|c|c|c|c|c|c|}
\hline \multirow[b]{3}{*}{ Plants $^{\mathrm{c}}$} & \multicolumn{9}{|c|}{$16 \mathrm{~S} \mathrm{rDNA} C \mathrm{CN} / \mu \mathrm{l}^{\mathrm{b}}$} \\
\hline & \multirow{2}{*}{$\begin{array}{l}\text { Rootstock shoots } \\
\text { Pool }^{\mathrm{d}}\end{array}$} & \multicolumn{4}{|c|}{ Leaves (hybrids) } & \multicolumn{4}{|c|}{ Roots (Rangpur lime) } \\
\hline & & A & $\mathrm{B}$ & $\mathrm{C}$ & $\mathrm{D}$ & A & B & $\mathrm{C}$ & $\mathrm{D}$ \\
\hline H69 & $7.99 \mathrm{E}+04$ & $1.22 \mathrm{E}+04$ & $3.76 \mathrm{E}+04$ & - & - & $2.58 \mathrm{E}+01$ & - & $1.34 \mathrm{E}+02$ & - \\
\hline H181 & $7.80 \mathrm{E}+04$ & $9.24 \mathrm{E}+01$ & $1.25 \mathrm{E}+05$ & - & - & $1.65 \mathrm{E}+04$ & - & $1.02 \mathrm{E}+03$ & - \\
\hline H03 & $1.92 \mathrm{E}+05$ & - & - & $6.20 \mathrm{E}+03$ & - & - & - & - & _- \\
\hline $\mathrm{H} 302$ & $3.64 \mathrm{E}+03$ & $7.40 \mathrm{E}+04$ & $4.06 \mathrm{E}+04$ & - & - & $2.01 \mathrm{E}+03$ & $2.39 \mathrm{E}+01$ & $4.37 \mathrm{E}+04$ & $4.71 \mathrm{E}+04$ \\
\hline $\mathrm{H} 123$ & $7.50 \mathrm{E}+04$ & - & - & - & - & - & $9.4 \mathrm{E}+02$ & $3.49 \mathrm{E}+04$ & $1.25 \mathrm{E}+02$ \\
\hline H129 & $1.44 \mathrm{E}+04$ & - & - & - & - & $1.02 \mathrm{E}+03$ & - & - & - \\
\hline H239 & $4.06 \mathrm{E}+04$ & - & - & - & - & - & - & - & - \\
\hline $\mathrm{H} 222$ & $5.38 \mathrm{E}+04$ & - & - & - & - & - & - & - & - \\
\hline H281 & $1.55 \mathrm{E}+04$ & - & - & - & - & $2.17 \mathrm{E}+03$ & $1.60 \mathrm{E}+03$ & $2.58 \mathrm{E}+01$ & $1.25 \mathrm{E}+02$ \\
\hline \multicolumn{10}{|c|}{ Neg shoots, Neg hybrid } \\
\hline H199 & - & - & - & - & - & - & - & - & - \\
\hline
\end{tabular}

a Detection of ' $\mathrm{Ca}$. L. asiaticus' in shoot, root, and leaf samples of ' $\mathrm{Ca}$. L. asiaticus'-negative and ' $\mathrm{Ca}$. L. asiaticus'-positive plants.

b Copy number $(\mathrm{CN})$ means of three replicates. A, B, C, and D = samples taken from four sides of the plants; - indicates undetermined cycle threshold value.

c 'Ca. L. asiaticus'-positive (Pos) or ' $\mathrm{Ca}$. L. asiaticus'-negative (Neg) shoots or hybrids.

${ }^{\mathrm{d}}$ Pool of 10 leaves from the shoots. 
roots before leaves, where it multiplied and quickly invaded leaves when new foliar flush became a sink tissue for phloem flow.

In this work, we detected variation in ' $\mathrm{Ca}$. L. asiaticus' incidence and ' $\mathrm{Ca}$. L. asiaticus' abundance among the genotypes, which can be interpreted as evidence of resistance or tolerance of $P$. trifoliata to ' $C a$. L. asiaticus'. However, we cannot conclude, in the case of citrandarin as scion, whether that resistance is in relation to bacteria or to psyllids. When the citrandarin hybrids were used as rootstocks, at least one of them with two replicates was ' $\mathrm{Ca}$. L. asiaticus' negative. These results seem encouraging; however, because of the importance of citrandarin in citrus breeding programs, future work will include an in-depth investigation to confirm the results and to study the probable mechanism of resistance, and identifying compounds or other mechanisms of defense in $P$. trifoliata and its hybrids. The aim will be to find a strategy to combat HLB.

\section{ACKNOWLEDGMENTS}

This study was conducted with the financial support of Fundação de Amparo a Pesquisa do Estado de São Paulo (FAPESP) (process numbers 2007/08435-5 and 2011/18605-0) and Instituto Nacional de Ciência e Tecnologia (INCT) de Genômica para Melhoramento de Citros (process number 573848/2008-4) and a Postdoctoral fellowship to L. Pires Boava (process number 2012/01917-2) from Fundação de Amparo a Pesquisa do Estado de São Paulo (FAPESP). M. Cristofani-Yaly and M. A. Machado are recipients of research fellowships from $\mathrm{CNPq}$.

\section{LITERATURE CITED}

1. Achor, D. S., Exteberria, E., Wang, N., Folimonova, S. Y., Chung, K. R., and Albrigo, L. G. 2010. Sequence of anatomical symptom observations in citrus affected with huanglongbing disease. Plant Pathol. J. 9: 56-64.

2. Albrecht, U., and Bowman, K. D. 2011. Tolerance of the trifoliate citrus hybrid US-897 (Citrus reticulata Blanco $\times$ Poncirus trifoliata L. Raf.) to huanglongbing. HortScience 46:16-22.

3. Albrecht, U., and Bowman, K. D. 2012. Transcriptional response of susceptible and tolerant citrus to infection with Candidatus Liberibacter asiaticus. Plant Sci. 185-186:118-130.

4. Albrecht, U., McCollum, G., and Bowman, K. D. 2012. Influence of rootstock variety on huanglongbing disease development in field-grown sweet orange (Citrus sinensis [L.] Osbeck) trees. Sci. Hortic. 138: 210-220.

5. Bassanezi, R. B., Montesino, L. H., Gimenes-Fernandes, N., Yamamoto, P. T., Gottwald, T. R., Amorim, L., and Bergamin Filho, A. 2013. Efficacy of area-wide inoculum reduction and vector control on temporal progress of huanglongbing in young sweet orange plantings. Plant Dis. 97: 789-796.

6. Boava, L. P., Cristofani-Yaly, M., Mafra, V. S., Kubo, K. S., Kishi, L. T., Takita, M. A., Ribeiro-A., M., and Machado, M. A. 2011. Global gene expression of Poncirus trifoliata, Citrus sunki and their hybrids under infection of Phytophthora parasitica. BMC Genomics 12:39.

7. Bové, J. M. 2006. Huanglongbing: A destructive, newly-emerging, century-old disease of citrus. J. Plant Pathol. 88:7-37.

8. Coletta-Filho, H. D., Targon, M. L. P. N., Takita, M. A., De Negri, J. D., Pompeu, J. J., and Machado, M. A. 2004. First report of the causal agent of huanglongbing ("Candidatus Liberibacter asiaticus") in Brazil. Plant Dis. 88:1382.

9. Cristofani-Yaly, M., Novelli, V. M., Bastianel, M., and Machado, M. A. 2011. Transferability and level of heterozygosity of microsatellite markers in Citrus species. Plant Mol. Biol. Rep. 29:418-423.

10. Dagulo, L., Danyluk, M. D., Spann, T. M., Valim, F. M., GoodrichSchneider, R., Sims, C., and Rouseff, R. 2010. Chemical characterization of orange juice from trees infected with Citrus greening (huanglongbing). J. Food Sci. 75:C199-C207.

11. Folimonova, S. Y., Robertson, C. J., Garnsey, S. M., Gowda, S., and Dawson, W. O. 2009. Examination of the responses of different genotypes of citrus to huanglongbing (citrus greening) under different conditions. Phytopathology 99:1346-1354.

12. Futch, S., Weingarten, S., and Irey, M. 2009. Determining HLB infection levels using multiple survey methods in Florida citrus. Proc. Fla. State Hortic. Soc. 122:152-158.

13. Gottwald, T. R. 2010. Current epidemiological understanding of citrus huanglongbing. Annu. Rev. Phytopathol. 48:119-139.

14. Gottwald, T. R., Irey, M., Gast, T., Parnell, S., Taylor, E., and Hilf, M. E.2010. Spatio-temporal analysis of an HLB epidemic in Florida and implications for future spread. Pages 84-97 in: Proc. 17th Conf. Int. Organ. Citrus Virol. University of California, Riverside, CA.

15. Grafton-Cardwell, E. E., Stelinski, L. L., and Stansly, P. A. 2013. Biology and management of Asian Citrus psyllid, vector of the huanglongbing pathogens. Annu. Rev. Entomol. 58:413-432.

16. Halbert, S. E. 2005. The discovery of huanglongbing in Florida. Page H-3 in: Proc. 2nd Int. Citrus Canker Huanglongbing Res. Workshop. Florida Citrus Mutual, Orlando, FL.

17. Halbert, S. E., and Manjunath, K. L. 2004. Asian citrus psyllids (Sternorrhyncha: Psyllidae) and greening disease of citrus: A literature review and assessment of risk in Florida. Fla. Entomol. 87:330-353.

18. Hall, D. G., and Richardson, M. L. 2013. Toxicity of insecticidal soaps to the Asian citrus psyllid and two of its natural enemies. J. Appl. Entomol. 137:347-354.

19. Johnson, E. G., Wu, J., Bright, D. B., and Graham, J. H. 2014. Association of 'Candidatus Liberibacter asiaticus' root infection, but not phloem plugging with root loss on huanglongbing-affected trees prior to appearance of foliar symptoms. Plant Pathol. 63:290-298.

20. Li, W., Hartung, J. S., and Levy, L. 2006. Quantitative real-time PCR for detection and identification of Candidatus Liberibacter species associated with citrus huanglongbing. J. Microbiol. Methods 66:104-115.

21. Mackay, I. M., Arden, K. E., and Nitsche, A. 2002. Survey and summary-Real-time PCR in virology. Nucleic Acids Res. 30: $1292-1305$.

22. Manjunath, K. L., Halbert, S. E., Ramadugu, C., Webb, S., and Lee, R. F. 2008. Detection of 'Candidatus Liberibacter asiaticus' in Diaphorina citri and its importance in the management of citrus huanglongbing in Florida. Phytopathology 98:387-396.

23. Mann, R. S., Ali, J. G., Hermann, S. L., Tiwari, S., and Pelz-Stelinski, K. S. 2012. Induced release of a plant-defense volatile 'deceptively' attracts insect vectors to plants infected with a bacterial pathogen. PLoS Pathog. 8:e1002610.

24. Mann, R. S., Rouseff, R. L., Smoot, J. M., Castle, W. S., and Stelinski, L. L. 2011. Sulfur volatiles from Allium spp. affect Asian citrus psyllid, Diaphorina citri Kuwayama (Hemiptera: Psyllidae), response to citrus volatiles. Bull. Entomol. Res. 101:89-97.

25. Murray, M., and Thompson, W. F. 1980. Rapid isolation of high molecular-weight plant DNA. Nucleic Acids Res. 8:4321-4325.

26. Patt, J. M., and Setamou, M. 2010. Responses of the Asian citrus psyllid to volatiles emitted by the flushing shoots of its rutaceous host plants. Environ. Entomol. 39:618-624.

27. Richardson, M. L., and Hall, D. G. 2013. Resistance of Poncirus and Citrus $\times$ Poncirus germplasm to the Asian citrus psyllid. Crop Sci. 53: 183-188.

28. Stover, E. D., and McCollum, G. 2011. Incidence and severity of huanglongbing and Candidatus Liberibacter asiaticus titer among field-infected citrus cultivars. HortScience 46, (10):1344-1348.

29. Su, H. J., and Huang, M. D.1990. The nature of likubin organism, life cycle, morphology and possible strains. Pages 106-110 in: Rehabilitation of Citrus Industry in the Asia Pacific Region. Proc. Asia Pac. Int. Conf. Citricult. B. Aubert, S. Tontyaporn, and D. Buangsuwon, eds. UNDP, FAO, Rome and Chiang Mai, Thailand.

30. Tsagkarakis, A. E., and Rogers, M. E. 2010. Suitability of 'Cleopatra' mandarin as a host plant for Diaphorina citri (Hemiptera: Psyllidae). Fla. Entomol. 93:451-453.

31. Wang, Z., Yin, Y., Hu, H., Yuan, Q., Peng, G., and Xia, Y. 2006. Development and application of molecular-based diagnosis for 'Candidatus Liberibacter asiaticus', the causal pathogen of citrus huanglongbing. Plant Pathol. 55:630-638.

32. Westbrook, C. J., Hall, D. G., Stover, E. W., Duan, Y. P., and Lee, R. F. 2011. Susceptibility of Citrus and Citrus-related germplasm to Diaphorina citri (Hemiptera: Psyllidae). HortScience 46:997-1005. 